\title{
SO, ONE OF THOSE TINY ALIEN SPACESHIPS HAS FLOWN INTO YOUR HOUSE. NOW WHAT?
}

\author{
A self-help guide.
}

\section{BY LAURA PEARLMAN}

$\mathrm{T}$ The best strategy is not to let them in, of course, but maybe you left your chimney flue open or didn't notice a hole in a window screen, and now there's a tiny alien spaceship flitting around your living room or kitchen or swooping under your diningroom table, and there's really no point in self-recrimination or speculation about which of your kids might have propped the front door open while they all loaded their cars up after Thanksgiving weekend, leaving you to rattle around alone in your empty nest once again.

However it happened, it's just you in the house with your two cats and something that looks like a miniature flying neonpink Roomba. The first thing you need to do is take three deep calming breaths, unless of course your cat is making that weird trilling noise they make when they see a bird, in which case the first thing you need to do is get your cat the hell out of there before it tries to pounce and the aliens blast it with one of their energy cannons.

Once you've got your cat safely shut in another room - maybe your bedroom, where your other cat is already cowering under the bed - and cleaned up any scratches you might have acquired in the process, you can go back to step one. Take three deep breaths and remind yourself that the vast majority of people who have these encounters survive, usually with only minimal injuries.

Try to stay out of the aliens' way. Let them take whatever they want. No one knows for sure what motivates them, but the prevailing theory is that they're on some kind of recreational scavenger hunt, collecting a seemingly random assortment of items such as rubber bands, peanuts, crayons, lipstick, toenail clip-

\section{ONATURE.COM}

Follow Futures:

y @NatureFutures

$f$ go.nature.com/mtoodm pings, blood samples and tears.

Don't fall into paranoid speculation about what the aliens are going to do with these items. They're aliens, not witches.

If you hear yowling or snarling coming from your bedroom, and you begin to regret confining your agitated cat and your terrified cat in the same room, undoing all

them directly. If the ship is hovering near any other part of your body, remain calm and let them harvest whatever biosample they need. Chances are, it'll be something small.

Apply direct pressure to the incision site(s). If the bleeding continues for more than five minutes, call 911, and an ambulance will be dispatched to your location. Be sure to mention that aliens are present and stay on the line until they leave. The aliens will incinerate anyone attempting to enter or exit, so it's important that the paramedics wait outside until the aliens are gone.

On a related note, keep all your exterior doors and windows closed and locked.

If the ship wants to enter the room in which you've confined your cats, you really have no choice but to let it in. Your cats should be terrified enough by now that they'll stay out of the aliens' way, and as long as they do, they'll be fine. The aliens seem to be completely uninterested in cats, which is one way we know they are aliens.

Eventually, the ship will hover near an exterior door or window. This means the aliens have collected everything they

the progress they've made in learning to get along together over the past three years just ignore it. You need to focus on the aliens.

Watch the ship and follow its lead. If it's repeatedly bumping against an interior door, cabinet or drawer, it wants what's inside, and your best course of action is to open the door or cabinet or drawer or whatever before the aliens get impatient and reduce your collection of stemware to a puddle of molten glass, including those nice champagne flutes you were planning to use just as soon as you had something to celebrate.

If you have a fire extinguisher, keep it to hand as you follow the aliens around the house.

If the ship is hovering near your eyes, remove your contact lenses immediately and place them on the nearest table or countertop. Seriously. You don't want the aliens to extract set out to collect, and all you need to do at this point is let them out.

Congratulations! You've survived your first alien encounter. Extinguish any smouldering fires. If you've called 911, let them know it's safe for the paramedics to come in. Give your cats some treats. Blot any bloodstained areas of carpet with a clean, dry cloth, then apply some club soda and blot some more. Text those friends you've been meaning to get together with, and pop over to the store to pick up a bottle of champagne.

Just remember to close the door behind you on your way out.

Laura Pearlman's work has appeared in Shimmer, Flash Fiction Online, Intergalactic Medicine Show and a handful of other places. You can find her on Twitter at@laurasbadideas. 